
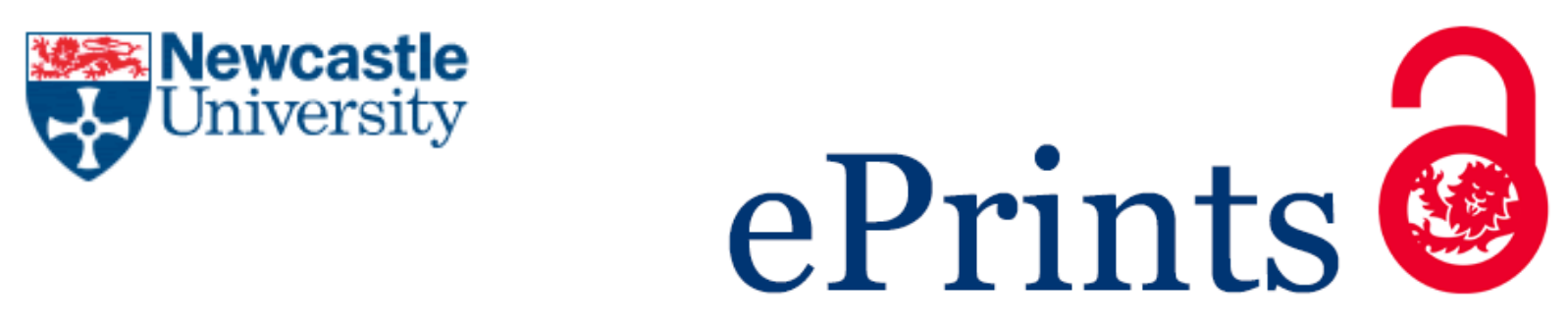

Shaw R.

Beyond Night-Time Economy: Affective Atmospheres of the Urban Night. Geoforum 2014, 51(1), 87-95.

\title{
Copyright:
}

(C) 2014. This manuscript version is made available under the CC-BY-NC-ND 4.0 license

DOI link to article:

http://dx.doi.org/10.1016/j.geoforum.2013.10.005

Date deposited:

$07 / 09 / 2015$

Embargo release date:

12 November 2015

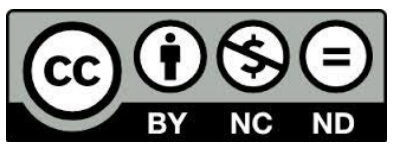

This work is licensed under a

Creative Commons Attribution-NonCommercial-NoDerivatives 4.0 International licence 


\section{Beyond Night-Time Economy: Affective Atmospheres of the Urban Night}

Keywords: Night-time economy; Assemblage; Affective Atmospheres; Urban Geography; Practices

'Assemblage urbanism' has come to the fore in attempts to bring together practice, affect and materialist oriented approaches to understanding what the city is and how it functions. Assemblage urbanism has emphasised the continuous construction and production of the city through practices and the movement of materials (Anderson et al., 2012; McCann and Ward, 2011; McFarlane, 2011). This places new questions at the centre of urban studies, as part of a wider shift in the epistemology of geography and social science. The key issues for research become: "how do things fit together and hold together across differences? How to think the irreducible contingency of order?" (Anderson and Harrison, 2010:18). This paper is an attempt to explore these questions in relation to the night time city. To date, research into the night-time city spread across criminology, geography, sociology, anthropology, history, epidemiology and more has captured and explored the changing nature of cities at night, as new sorts of spaces, which Chatterton and Hollands (2002) label as playscapes. These have developed according to urban governance strategies that have prioritised the creation of large (chain) bars, pubs and restaurants. Research has mainly centred on the British and Australian contexts, though it has also explored night-time cities in Europe, North America and East Asia. Through this research, 'night-time economy studies' has had a close affinity with alcohol studies (Jayne et al., 2008; Nicholls, 2009). Reviews of progress of this field in the last five years (Jayne et al., 2011a; Roberts and Eldridge, 2009) have indicated indicating a certain level of academic maturity in this field, mirroring an end to a period of growth in England of alcohol consumption in the urban night.

Approaching the urban night from an 'assemblage urbanism' position, however, can raise the question of whether this area of research has been too quick to equate the urban night with the night-time alcohol and leisure industry ('the night-time economy'). Rather, there may be space to explore how non-economic and non-alcohol based practices intersect with more visible features of the urban night. In doing so, I add recent work on atmosphere (Anderson, 2009; Bissell, 2010) into the assemblage-related vocabulary, arguing that this offers a particularly geographical understanding of the role of assemblage in the city. My work also builds upon recent attempts to begin to push research into alcohol and the night in new directions, incorporating the affective and atmospheric dimensions of night-time cities (Edensor, 2012; Eldridge and Roberts, 2013). In this paper, my empirical focus remains on the night-time alcohol and leisure industry. However, it does so by focusing not on the night-time city as a singular 'economy', but as an 'affective atmosphere'. I work through a mixture of theoretical and empirical exploration, drawing on my research with taxi drivers and street cleaners in the city centre at night in order to explore both how atmospheres of the city centre are generated, and also where they start to spill out and connect to the rest of the city. Developing this, I then argue that if we understand an affective atmosphere as a form of 'placed assemblage', we can create a powerful tool for using assemblage-as-description of the nighttime city. In other words, I argue that certain assemblages emerge from multiple practices which collaborate and gather together to control a time and place, producing particular 'affective atmospheres'. Many features of what has previously been labelled the 'night-time economy' are then better understood as one such atmosphere, a placed assemblage developed out of multiple practices of which the sale, regulation and governance of alcohol is just one part. 


\section{Assemblage Urbanism and Atmosphere}

Though geographers and people in urban studies have been working with the ideas of Deleuze and Guattari for several years (e.g. Doel, 1996; Nandrea, 1999), the concept of assemblage has come to the centre of attention only more recently, in conversation with the multiple other forms of 'relational' geography that now dominate the discipline (Harrison, 2011). This slow emergence and conversation between multiple perspectives means that the contemporary concept of assemblage in urban geography is not a simple development of the word 'agencement' from Deleuze and Guattari (Deleuze and Guattari, 1987; Phillips, 2006). Particularly, it also incorporates: perspectives which focus on the notion of daily life and the urban as 'assembled', that is, as constantly in-production (McCann and Ward, 2011); and the vocabulary of actor-network theory, in which the topic of study is the way in which society is brought together, that is, assembled (Latour, 2005). Crucially, assemblage in all its forms is interested in "a process of emergence, process and stabilisation, and connotes a sense that relations might be reassembled through changing forms of authority" (McFarlane, 2009:261). In this section, I want to offer a brief review of assemblage, noting that a number of articles in recent years have attempted to offer much longer and more in-depth explorations of the idea (Anderson et al., 2012; Anderson and McFarlane, 2011; McFarlane, 2011; McFarlane and Anderson, 2011), before focusing on how it might connect to and be brought into contact with the concept of 'atmosphere'. From here, I will move on to discussing work on nighttime economy and, through my empirical examples, explore the different ways of understanding the night-time city that this offers.

Deleuze and Guattari use the term agencement, which is translated as assemblage (Deleuze and Guattari, 1987; Phillips, 2006). For them, assemblage is "larger than structure, system, form, process etc. An assemblage contains heterogeneous elements on a biological, social, machinic, gnoseological, or imaginary order" (Guattari, 2006:415). In this quote Guattari details the complexity and depth of assemblage, which here is referring to both object and process. It is worth noting, as Phillips does, that Deleuze and Guattari do not use the French word assemblage (Phillips, 2006). The word agencement comes from adding a common suffix ('-ment') onto the verb agencer, translating as 'to arrange'. Arguably, a more suitable translation of agencement might thus be 'arrangement' or in a gerund form of '(an) arranging'. Indeed, assemblage fits perhaps best to the linguistic sense of the gerund in English, which can act in a sentence as subject, object or verb. So while Deleuze and Guattari typically write of assemblage as a noun, the word contains within it a strong sense of verb. It is this way in which it is possible to consider "assemblage as ethos", in which ethos is "potentially a commitment, a 'style', a form of responsibility or generosity" (Adey, 2012:200), in other words, both noun and verb. Assemblage thus offers a combination of structure and process, forming contingent, vibrant arrangings that we interact with on a daily basis, both in their 'structural' form, and their 'processual' form. Here assemblage is thus about arranging co-existences: about how the stable and the unstable, the solid and the light interact to produce the thing.

An assemblage is located both in objects and practices that we can identify in the world, and in the realm of the potential, containing aspects which have not yet been realised. To return to Deleuze and Guattari's terminology, "one side of a machinic assemblage faces the strata, which doubtless makes it a kind of organism, or signifying totality, or determination attributable to the subject; it also has a side facing a body without organs, which is continually dismantling the organism, causing asignifying particles or pure intensities to pass or circulate" (Deleuze and Guattari, 1987:4). Crucially, 
this understanding of assemblage incorporates two aspects that are unique to the DeleuzoGuattarian formation, and are not necessarily found in other uses of 'assemblage'. First, this requires that we consider the 'lively' (Bennett, 2005) nature of assemblages: assemblages in Deleuze and Guattari are of "lines" (Deleuze and Guattari, 1987), of moments of meeting between different things. In other words, we are not looking at permanent connections between domains of practices, but the instances or places in which they sometimes meet. Second, assemblages in Deleuze and Guattari are ambivalent, that is, they incorporate both those practices which support an assemblage and those which undermine it. Returning again to Guattari, he describes assemblages as being "of possible fields, of virtual as much as constituted elements" (Guattari, 1995:46). In other words, assemblage demands that we do much more than consider the networked relations between domains of practice. Rather, we need to explore where these relations form, where they fail to form, where they may form, where they cannot form, and so on.

While my understanding of assemblage sits most closely to that of Deleuze and Guattari, it should also be noted that other uses of the term share much with 'agencement'. For Latour, the task of the social researcher is one of 'reassembling' the social (Latour, 2005). Latour's assembling is used to define the social, that is, "a stabilised state of affairs, a bundle of ties" (Latour, 2005:1). Through assembling, associations are created and from here the social emerges. While Latour's use of the assembling verb comes very close to Deleuze and Guattari's agencement, he does not use a concept that is similar to 'an assemblage', with the 'actor-network' being closest to this. An actor-network, however, seems to be more 'concrete' than an assemblage, giving priority to the actions that either have or haven't happened, rather than possible actions. In particular, Latour's work contains little of the sense of 'becoming' or the 'virtual' that is found in Deleuze and Guattari: as Harman argues, "A thing is real for Latour only if it affects and perturbs other things" (Harman, 2009:106). Nevertheless, this is a relatively subtle distinction: most uses of assemblage in social science arguably have some sense of both Latour's and Deleuze and Guattari's formulation in mind simultaneously.

So assemblage involves within it an understanding of how co-existence occurs (McFarlane, 2009:562), that is, it looks at how objects, agents, affects and discourses are gathered together. While this gathering is not inherently 'geographical', in other words, it is not always about things being gathered proximately to one another, equally the question of where these items are gathered is also an important one. Certain assemblages are placed, that is, they come to be located in and potentially to take over a particular time-space. These assemblages have, to borrow a phrase, their 'own space' (de Certeau, 1984). I argue that such assemblages seem to be very close to how academics have in recent years described atmospheres, with atmosphere best understood as a geographical phenomenon in which a particular assemblage 'gains place'.

As Brennan suggests, common-sense understandings of atmosphere describe it as something which is 'felt' when an individual enters a place (Brennan, 2004). The concept of the atmosphere, or the 'affective atmosphere', has received a significant amount of attention in recent years in geography (Adey and Bissell, 2010; Adey et al., 2013; Anderson, 2009; Bissell, 2010; McCormack, 2008). Concerns about atmosphere have emerged as writers on affect have attempted to explore further the relationship between space and bodies and, specifically, how changes in the constitution of a space, whether in its characteristics or in the bodies within it, alter the affective experience of these spaces. Atmospheres are thus understood as: 
"generated by bodies - of multiple types - affecting one another as some form of 'envelopment' is produced. Atmospheres do not float free from the bodies that come together and apart to compose situations. Affective qualities emanate from the assembling of the human bodies, discursive bodies, non-human bodies, and all the other bodies that make up everyday situation." (Anderson, 2009:3).

Here, atmosphere seems to be closely connected to assemblage. Like an assemblage, atmospheres come from the bringing together of different 'bodies'. Here, Anderson is using bodies in its broadest sense, to refer to objects, discourses, people and animals. Unlike assemblage, however, atmospheres are always geographical, controlling but confined to a particular place, and often period of time. So as Bissell argues, atmospheres have "a pull or a charge that might emerge in a particular space which might (or might not) generate particular events and actions, feelings and emotions" (Bissell, 2010:273, my emphasis). In Bissell's quote, it is also worth noting that while an atmosphere may dominate, it is also not in total control: atmospheres have a potential to be felt. Finally, the relationship between practice and atmosphere should be mentioned. As atmospheres emerge from bodies, they are connected to the activities of those bodies: what Edensor labels the "reiterative practices" which "coproduce" atmosphere (Edensor, 2012). Perhaps contrarily, the atmosphere helps 'ground' affect, by showing how experiences which may appear ephemeral, loose and floating are often associated with material practices, bodies and places.

Work is required for an assemblage to control place, to become an atmosphere. Deleuze and Guattari identify four ways in which 'refrains' connect or disconnect assemblages to place, describing these as 'territorial motifs' and citing the example of birdsong as a practice which simultaneously achieves both of these roles (Deleuze and Guattari, 1987:357). Overall, Deleuze and Guattari identify four ways in which assemblage is translated into territory, that is, four different types of work which can produce atmosphere. These are: “(1) territorial refrains that seek, mark, assemble a territory; (2) territorialized function refrains that assume a special function in the assemblage...; (3) the same... [can] pass into new assemblages; (4) refrains that collect or gather forces" (Deleuze and Guattari, 1987:360). In this paper, I want to explore how certain practices in the urban night take on these roles in tying an assemblage to place, and thus producing an atmosphere. These roles can be called: border making ("seek, mark, assemble"); definition ("assume a special function"); breaking ("pass into new assemblages") and entrenchment ("collect or gather forces"). These functions are not mutually exclusive, and it should be expected that there is some overlap between them. Using these ideas, however, we can move on to explore the current state of night-time economy studies, before looking at how the urban night might be better understood as atmosphere.

\section{Night-Time Economy Studies}

Before moving on to discussing the possibility that assemblage thought and atmosphere might offer for understanding the urban night, it is worth exploring current 'night-time economy studies'. This phrase refers to the mixture of social science studies of alcohol and social science studies of the night-time leisure industry that has come to dominate how we understand night-time cities. I want to argue that under an assemblage urbanism approach, this area of research can be understood as closing down the assemblages which make up the night-time city. By making the object of study the 
'night-time economy', the city at night is reduced, first, to just the bars and clubs which make up city centres, and second, to the 'economic' ways of relating between these. Even studies within this area which offer a more diverse empirical perspective or which have integrated new theoretical approaches into night-time economy studies (Jayne et al., 2010) have not, I argue, challenged the underlying framework of 'night-time economy' itself.

As a phrase for describing the alcohol and leisure industry in the night-time city, the term 'night-time economy' has its origins in the work of the academics associated with Charles Landry's creative cities research organisation Comedia. Franco Bianchini, one of the academics involved in Comedia at the time, dated the term to 1987 and the Italian politician Renato Nicolini, who had been responsible for a series of cultural festivals, including night-time activities, in Rome called 'L'Estate Romana' between 1977-1985 (Bianchini, 1995). This would fit with academic publications: the phrase does not appear in the 1986 book on British cultural policy Saturday Night or Sunday Morning (Mulgan and Worpole, 1986) but is used in a 1990 article on cities and cultural planning by John Montgomery (Montgomery, 1990). From this, it is clear that night-time economy first gained currency in planning circles. Specifically, the term's circulation was associated with the attempts of groups such as Comedia to encourage the deregulation and development of the alcohol and leisure industry at night (Bianchini, 1995; Comedia, 1991; Heath, 1997) in both political and academic fields. As Bianchini states:

\begin{abstract}
"In the case of important regional cities the night-time could be used to maximise access to urban facilities from a wide catchment area. People from that area, many of whom are working in the daytime, may need longer opening hours in order to access facilities. More generally, there is the opportunity of 'doubling' the city's economy, starting perhaps from entertainment but then widening into other areas" (Bianchini, 1995:124)
\end{abstract}

It is the opportunity to 'double' the city's economy, by doubling the period of time by which city centres are productive, that is at the heart of the argument for a night-time economy raised by Bianchini and others. Furthermore, this phrase's formulation is connected to the discursive power of the word 'economy' (rather than alternatives such as nightlife or night-time culture), particularly as this attempt to promote the urban night as a source of cultural production occurred during the recovery from the early 1990s recession in the UK.

The term 'night-time economy' was initially used with a sense of hope: Bianchini, and Comedia, more broadly, were speaking of a multi-industry night, in which alcohol and leisure would form only a portion of activity (Bianchini, 1995). In a 2002 interview with John O'Conner, one of the academics working with Comedia, reaffirms this intention: "The whole issue of a diverse and high quality provision of different leisure, entertainment and cultural services outside the 9-5 period has been missed" (Roberts and Turner, 2005:190). For O'Conner, the hope and promise of the night-time economy was never fulfilled due to its elision with the alcohol and leisure industry. As Hadfield et al. claim in a very quotable comment, the "Mass Volume Vertical Drinker has assaulted the concept [24hour city] and all its good intentions, leaving it for dead in streets splattered with blood, vomit, urine and the sodden remains of take-aways" (Hadfield et al., 2001:300). In other words, this night-time economy was intended to be much more than the night-time high street which developed, and as a project can be said to have largely failed in its initial aims. As I have argued elsewhere [reference 
removed for anonymous review purposes] this failure stemmed in part from the neoliberal 'hijacking' of this movement: the opening up of a new-time space for multi-purpose activity was replaced by the opening up of one market (the sale of alcohol) in order to encourage consumption (see also Hadfield, 2006). It has also been convincingly argued that a failure to take into account culture, and specifically drinking culture, contributed to the failure of this project (Jayne et al., 2011a; Nicholls, 2009; Roberts, 2006; Roberts and Eldridge, 2009).

Thus, while much of this writing has been critical of the night-time economy, and the way in which alcohol consumption has been problematized as solely a health problem (Jayne et al., 2011b), so too does it retain a central focus on 'night-time economy' and associated alcohol consumption. This move is problematic in the epistemologies of the night that it encourages. By continuing to centre the economic, such critiques unintentionally repeat the dominance of the night-time alcohol and leisure industry. (Gibson-Graham, 2008). It is important to recognise, then, the performative nature of terminology, in which names and labels such as 'night-time economy' help to produce the arena which they describe. As Latour argues, "whereas there is no independent domain of science, technique, law, religion, etc., it makes a huge, a lasting, an enormous difference whether a connection is made legally, scientifically, religiously, artistically, politically or technically" (Latour, 2007:7-8). In other words, while the night-time economy may not exist as an independent domain, it makes a huge difference to describe and connect certain aspects of the night economically. The phrase 'night-time economy' was created in order to 'sell' cultural production in the night to local and national authorities in the UK in the early 1990s (Hadfield, 2006). Even where city authorities might have desired diverse 'night-time economies', in practice it was the alcohol and leisure industry which was best placed to take up the cheap development opportunities that were available, while local authorities often had little power to influence planning decisions that would prevent this (Hadfield et al., 2001; Vall, 2007). Researchers who continue to use the phrase night-time economy, and who continue to centre the economic when studying the urban night, do not move beyond the dominance which came from this. In this paper, I use 'night-time alcohol and leisure industry' to refer to the alcohol and drinking industry at night, to emphasise that it forms just a portion of the urban night. This also reflects that much of 'night-time economy studies' remains very close to 'alcohol studies', to the extent that it might in its current form be seen as a sub-field of alcohol studies.

\section{Night-Time Economy as Night-Time Atmosphere}

While the above section critiques the use of the term 'night-time economy', here I want to more systematically apply the concept of assemblage to the night-time city, exploring the specific problems that have emerged out of the dominance of the phrase 'night-time economy' and the associated approach to studying the night-time city. I will then explore how 'atmosphere' can be a better description of the night-time city centre, before drawing from research in Newcastle-uponTyne to explore how practices can assemble and maintain an atmosphere in the city at night. In doing so, I seek to move beyond a simple call for the proliferation of actors: while this is important, I do not feel that researchers simply need to include a wider series of practices, people and objects in their vision of the night-time city. Rather, as I seek to develop in this section, an assemblageoriented approach offers an alternative vision of the night-time city as an urban atmosphere. 
Following my above discussion, two major limits to current 'night-time economy studies' emerge. The first is that it tends towards locating problems associated with the night-time city - namely, antisocial behaviour and alcohol-related health problems - in the governance and alcohol and leisure industry (Hobbs et al., 2005:263; Measham and Brain, 2005; Talbot, 2007). While there is clearly a relationship between regulation, policing and alcohol consumption, historical analysis also shows that any regulatory changes are filtered and shaped through mundane practices of consuming alcohol (Nicholls, 2009). As noted previously, the work of Jayne, Valentine and Holloway has offered an alternative attempt to explore a variety of different cultural contexts in which drinking occurs, in an attempt to problematize the narrow view that has been taken into research on alcohol (Jayne et al., 2011a). Nonetheless the field is characterised by a tendency towards a reductio ad alcohol, which brings all of the political and social issues related to the urban night down to issues surrounding alcohol retail and legislation. This "reified discourse of nights within cities" (Gallan and Gibson, 2011:2514) presumes the night-time city is presumed to be only those spaces which make up and surround bars, pubs and clubs of a city. The second limit to night-time economy studies therefore emerges, with locations, actors and practices not directly associated with alcohol often displaced. Where additional actors have been added in - bouncers (Hobbs et al., 2003), tourists (Bell, 2008), CCTV surveillance cameras (van Liempt and van Aalst, 2012), stag and hen parties (Thurnell-Read, 2011) - it is still alcohol and night-time economy which has tended to remain the foundational topic of study. There are relatively few studies which into the alcohol and leisure industry at night which have begun to move beyond a focus on regulation and the city centre (Hubbard, 2005). The areas of study that have seen most 'cross-over' research in relation to the alcohol and leisure industry at night have been sexuality (Waitt et al., 2011) and drugs (Hubbard, 2005; Jackson, 2004; Measham and Moore, 2009). What is notable here is that these papers broaden study with a focus on 'practices', which begins to move the discussion of urban nights into new areas (for an example of an alcohol-oriented paper which does focus on practice, see Jayne et. al., 2012). Nevertheless, night-time economy studies still presents as a whole an empirically narrow view of the urban night.

For these identified limitations, drawing from a form of assemblage urbanism can offer a fresh approach. An assemblage approach requires a questioning of emergence: how do city centre and night emerge together? What practices and materials constitute the night-time city centre, and what practices and materials run counter to the overall direction of city centres at night? In other words, this approach questions more completely the foundation of 'night-time economy', rather than taking the night-time city as an unproblematic background (Gallan and Gibson, 2011). In the night-time city, the night is an experience of "excitement, expectation, apprehension, tension" (Malbon, 1999:x), in which the night-time city becomes a space for 'constrained hedonism' (Griffin et al., 2009). For those on the outside looking in, these places appear to be 'no-go areas' (Roberts, 2006), in which wild and dangerous behaviour takes control of the city centre for a period of time. Hadfield perhaps best expresses this when he talks of the process of conducting participant observation research in the night-time city:

"In the course of my visits to over fifty high street premises over a four-year period ... I became attuned to those aspects of the social and physical environment indicated by the research literature and by my own experience, to be associated with alcohol-related crime and other forms of 'stress'”' (Hadfield, 2006:276) 
Here, 'becoming attuned' to the environment is the process of becoming aware of the affective components of the atmosphere, which are driven by the various materials and bodies that are gathered together in the night-time city centre. As these materials gather together, affects are transmitted between them, transforming the assemblage into atmosphere. These assemblages then become entrenched, with boundaries being drawn to strengthen them. In the case of the night-time city, these boundaries are constructed in space and time - as Hadfield and Lister state quoting the band 'Arctic Monkeys': "This town's a different town today" (Hadfield et al., 2009). In other words, the day and night-time city differ due to the practices and materials which create boundaries within which assemblages can connect to space, and within these boundaries maintain the resultant atmosphere. The affective atmosphere is thus subsequent to a series of orderings, constructions and bringing together. In the subsequent empirical material, I want to look at how some of these ways of brining the assemblage together into an atmosphere take place in Newcastle-upon-Tyne at night.

\section{Generating the Night-Time City Atmosphere in Newcastle-upon-Tyne}

Newcastle-upon-Tyne is a city with what has been labelled a 'traditional working-class drinking culture' (Vall, 2007). This culture is centred on pub-based weekend drinking by both men and women, and reflects the wider drinking culture that has emerged in the UK since the early 1990s. With heavy weekend drinking in the city centre a feature of Newcastle's drinking culture before this trend spread nationally, the socio-spatial biography of the city already provides a space suitable for the entrenchment of the affective atmosphere of the city's night, with Newcastle gaining a reputation as a 'party city'. Perhaps as a result of its reputation, Newcastle's nightlife is one of the more heavily studied in the UK (Chatterton and Hollands, 2001; Hollands, 1995; Nayak, 2006; Pain and Townshend, 2002). It has seen significant growth from the 1990s, and is now a heavily regulated and managed part of the local economy. This background is important as atmospheres, while often ephemeral and affect-driven, emerge from culturally contingent representational context: that is, the "cumulative processes through which affect in place is experienced" (Edensor, 2012:1105). While the practices, materials and affects which generate Newcastle's night-time might be repeated elsewhere, the specific emergent atmosphere is unique.

The research used in this paper comes from a larger project studying the night-time city centre of Newcastle. The research was not carried out with the framework described above in mind; rather, this emerged during and after the research. While drawing on similar literatures to those used in this paper, the research retained an alcohol and night-time economy focus. As such, the empirical material drawn upon in this paper is used in an explorative way, as vignettes or moments which show how atmosphere gains place through an arranging in the city. While the actual material does thus not take us far from existing research into the urban night, this also has the advantage of showing how an alternative conception of the night-time city can help alter our approach. The specific material drawn upon here is based upon two sections of the research. First, I have drawn from 1 month of participant observation in the control room of a regional taxi firm. This consisted of three-four visits a week, each lasting around five hours and across the month covering a full range of times between 18:00-05:00. In addition to the participant observation, I also conducted interviews and a focus group with six taxi drivers from a different taxi firm in the city, exploring their experiences of working in the city centre at night. Second, I have used my research with Newcastleupon-Tyne's Neighbourhood Services Night Team, that is, the city centre's street cleaners. This involved repeated participant observation with staff both in their depot and out on the streets on a 
recurring basis over 6 months. In total, I conducted 13 participant observation visits, in addition to two interviews with managers on the team and informal interviews conducted during the participant observation. All of this research took place in the context of a longer piece of 18 month participantobservation in Newcastle-upon-Tyne at night. The research is presented in order to illustrate different practices involved in creating the atmosphere of the night-time city, rather than to explore specifically the work of these groups in the night. In exploring how the atmosphere of the nighttime city emerges, I draw on the four different roles that practices can take as suggested by Deleuze and Guattari (Deleuze and Guattari, 1987).

\subsection{Border Marking}

'Border-making' refers to practices which, according to Deleuze and Guattari, "seek, mark, assemble" an assemblage within a territory. These practices bring bodies together, generating the spatial proximity which is required for an atmosphere to emerge. By bringing these bodies together a boundary to an atmosphere can begin to emerge, although this will usually be a broad porous boundary. Once such a boundary begins to emerge, further practices can reinforce it and thus strengthen the atmosphere. The following extract from my research diary seeks to illustrate this:

"In the taxi offices, an operator collects a phone call. "Hello Eastwall Taxis, this is Alison speaking. [pause] And where would you like that from? Bar Blanc?" There is a pause as she enters this bar name into a computer. The computer searchers through its database of bar locations in Tyne and Wear and pulls up a probable match. "And that's on Osborne Road in Jesmond is it?" ...The booking is entered at the computer; up through wires and cables, the information goes to two large cupboard-sized servers - the floors of Eastwall's building needed reinforcing to hold them. This travels back down the wires to the central dispatch computer, which logs the booking within its given time period. Twenty minutes later, the booking has moved up the priority list and is the next booking to be allocated. Eastwall's GPS system identifies a car which is due to become available in the Jesmond area, and, once the driver has declared their previous fare finished, s/he receives the details of the booking. ... The computer in Eastwall Taxi's offices retrieves the phone number of the customer and sends a text with the details of the driver's taxi. The customer in Bar Blanc receives the text. A few minutes later it is confirmed that the driver has picked up the customers." These practices in distant spaces interact with the city centre to generate atmosphere. Groups of people pour out of taxis which have taken them from suburbs, into the city centre. Already drunk from either their local pub-crawl or home based 'pre-loading', ${ }^{1}$ these groups quickly liven up an already busy city centre. As people travel the other way, taxi ranks for Hackney Carriages become late-night pinch points of crowds and violence. As people travel home in taxis, the intense atmosphere of a busy city-centre at night is quickly dispersed via bodies which, through their separating, quickly lose hold of the affects that had previously enveloped them.

Taxis are central to mobilities in the urban night (Cooper et al., 2010), giving them a key role in bringing people and objects into a particular area. In other words, they assemble the bodies required to generate atmosphere (Anderson, 2009). The offices of 'Eastwall Taxis' - a pseudonym - attract more than one thousand calls an hour during a busy weekend night, and they find themselves running an hour behind demand at peak times, despite having seventy vehicles out at any given

\footnotetext{
${ }^{1}$ Pre-loading refers to consumption of significant amounts of shop-brought alcohol at home, benefitting from the cheaper prices that off-licence retailers are able to offer (Boyle et al., 2009).
} 
moment. Eastwall, a private hire company, are exemplary of the kind of taxi firms whose existence in the UK has only become possible over the last ten years, thanks to developments in technology. Inputs from a series of sources - phone operators, dispatchers and drivers - allow software to locate drivers, allocate fares and inform dispatch staff of their completion. Customers who book via their mobile receive texts describing the car which is due to collect them. During my time in the company's offices as an ethnographer, only once did they have to turn a city map. Using a mixture of technology and learnt experience of the city, drivers can operate over a much wider geographical spread than many of their rivals; whilst other companies with whom I researched had to reject fares in certain locations, Eastwall were able to collect fares all over Tyne and Wear, including those that neither started nor terminated in either the city centre of Newcastle or their suburban base.

By bringing bodies together, and then by pulling them away, taxis contribute significantly to the temporal boundaries in the night-time city. At the start of the night, taxis allow people to make their way to the city centre relatively late, having consumed their alcohol elsewhere (Chatterton and Hollands, 2001; Hollands, 1995)., This pushes the temporal border of the night back a little - it allows people to arrive later into the city centre. As such, these practices contribute to the emergence of bustling, flexible atmosphere, but one which is intensified within a small time-space. This, then, has the effect of reinforcing the strength of the night-time city atmosphere, by assembling bodies together in a short-enough timeframe to allow for the atmosphere of the nighttime city centre to grow.

\subsection{Defining and Entrenchment}

I have categorised these two roles of practices together. Defining is my name for those practices which Deleuze and Guattari describe as taking on a particular role in an assemblage: "territorialized function refrains that assume a special function in the assemblage" (Deleuze and Guattari, 1987:360). In the context of the formation of an atmosphere, such practices are those which either take on a particular function which helps the atmosphere persist, or which are discursively marked in certain ways so as to encourage the perception of an atmosphere. Entrenchment, meanwhile, are those practices which function to tie an atmosphere more closely to a particular place ("refrains that collect or gather forces"). I bring these together in order to highlight that these four functions of practices are not separate: they are analytical and descriptive tools, rather than distinct moments or actions which can be fully independently identified, which is why their roles can be seen to cross over somewhat too.

Night-time street cleaning may be envisioned as a background activity with little to do with the generation of atmosphere of a city: it has been characterised as "cleaning the streets and collecting rubbish in the early morning when fewer people are about" (Adams et al., 2007:203). Nevertheless, while its role might be less obvious than the illuminating of space (Edensor, 2012) or the music played in bars (Hadfield, 2006), it is nonetheless important. In Newcastle, a team of night-time street cleaners can be found scattered across the city centre among the crowds queuing for bars and clubs. Moving between groups, they respond to the atmosphere by avoiding conflict with rowdy groups, and interacting playfully with those who seem more amiable. Leaflets are swept up and collated to be gathered by machines; individual cleaners with litter pickers walk round the edge of bar entrance ways, collecting cigarette butts from the floor. Their purpose is simple: to manage and contain the excessive flows of material that are produced from the atmosphere of the night-time city. The street 
cleaners in Newcastle city centre are thus involved in a task of management, attempting to keep an ever spiralling mixture of leaflets, food packaging and bodily fluids under control. On the night-time city streets, cleaners can be understood as having to literally mop up the excess parts of the assemblage of the night-time alcohol and leisure industry.

The street-cleaners take on a defining role in the night-time city atmosphere by preventing the excess associated with the night-time city from overwhelming it. The affective atmospheric excess is matched by a material excess as well. This spills all over the place, and not just directly though urination or vomiting (Eldridge, 2010). Bars and clubs send out teams of leafleting staff offering cheap alcohol deals or offers: most of these leaflets are immediately dropped onto the floor. These then mix with the grease from fast food packaging (see figure 1), the need for which has been created in part by the high consumption of alcohol. Here, we see the bars and clubs generating a range of different excesses which spill out onto the wider city streets: this becomes a moment in which the alcohol and leisure industry's relationship with the rest of the city is potentially undermined. Street cleaners, take on the role of maintaining the alcohol and leisure industry by incorporating these materials into a different assemblage of waste management. In combination with their Swingo vehicles, the cleaners form a machine to produce waste out of the night-time alcohol and leisure industry. In doing so, this machine maintains the city centre at night and allows the atmosphere of excess to form. Figures 1 and 2 capture the extent to which this excess can develop:

\section{Figure 1: Leaflets stuck onto floor with waste food grease}

[Insert Figure 1]

Figure 2: Vomit and urine corroding stone at The Gate Entertainment complex

[Insert Figure 2]

If this work defines the night-time city centre atmosphere, it also helps entrench it. When morning comes, city streets are largely empty, so that few people would be aware of the excess that has passed before. By preventing the affects of the night-time city centre to spread out, this results in an entrenchment of these affects within the city centre space. This entrenchment is also thus closely connected to boundary making, as discussed previously: it 'gathers forces' into a particular moment and holds them there. In doing so, night-time street cleaning supports the psychological entrenchment that has been identified in research as associated with the urban night. As Griffin et al. state, the night-time city is defined by "the pursuit of pleasure and hedonistic excess in bounded urban 'wild zones'" (Griffin et al., 2009:503) as drinkers look for a "controlled loss of control" (Measham and Brain, 2005:273). These ways of testing or experimenting with subjectivity in the urban night (Shaw, 2010) are possible because of the strong atmosphere created by the entrenchment of these affects within the night-time city centre. If these affects were allowed to spill out into the rest of the city, the strength of the affective atmosphere would be weakened, and thus the ability to use this time-space as a zone for controlled loss of control would be reduced.

\section{$\underline{4.3 \text { Breaking }}$}

If taxis help make and assemble the night-time city centre atmosphere, they can also break through the boundaries of it, and attach it to elsewhere. Here, breaking refers to the process of "pass[ing] in 
to new assemblages" (Deleuze and Guattari, 1987:360). As such, it is not just about assemblages collapsing, but about transfer between assemblages. In the urban night, as an atmosphere which is inherently bounded in time and space, a number of different practices bring it to an end. Taxis can act as objects which 'punch' through atmospheric boundaries as they move between city centre and suburb. As noted earlier, this makes taxis a major part of dispersing the night-time atmosphere as bars and pubs close. Police in Newcastle make use of this feature in the evening by using taxis as part of their implementation of 'Direction to Leave' notices or 'Dispersal Orders'. These orders give the police the power to disperse groups and to remove people from a certain area during the night (Helms et al., 2007). If someone is given such an order, they are prevented from being in a designated area for a period of time. These are used for low-level crime or for people who are extremely drunk, with the measure being used in order to reduce the possibility of crime. By removing a body from the atmosphere of the city centre at night, such orders nullify the affective capacity of these bodies. For the drivers, however, the use of these orders can be problematic. Such a tactic is often used to remove intoxicated individuals who have the potential to cause trouble, as an alternative to locking them in the cells for the night. This process, however, only reduces the affective capacity of these drunken bodies to act within a certain space. The bound-up capacity for affect in the agitated drunken body is shifted to the (confined) space of the driver's vehicle. Interviews suggested that these passengers were the most likely to be problematic when in the back of the cab: "We get take these passengers out of the city centre, which is fine like, we don't really have much choice. But they're always agitated, bound up. It's them I like taking least" (Newcastle taxi driver, Male). Taxis, here, thus transport the atmosphere of the city centre around the wider Newcastle and Tyneside area, punching through some of the boundaries and acting as vectors along which this affectivity of the night-time city can travel.

However, breaking practices can also rupture an atmosphere. The presence of street-cleaners can sometimes interact awkwardly with the 'controlled loss of control' of the night-time city. During rides in the Swingo cleaning vehicle, I experienced the fractious atmosphere that came from the conflicting mobilities of the vehicle and the people on the streets. As we drove round, people regularly walked in-front of us, both deliberately and by accident: some asked for lifts, others refused to move from our way. People would drop litter playfully in front of us, or bash on the sides of the vehicle as we passed. Distinguishing between those who found the presence of the Swingo an amusing, incongruous insertion into the night-time city, and those who found it an annoying impediment to their enjoyment, was particularly difficult. Here, the mobilities of the institutional, bulky and official vehicle contrasted with the spontaneous, unthinking mobilities of the walking, drunken crowd. Such breaks and interruptions can reveal that the night-time city centre is thus vulnerable to sudden shifts, that the hold of assemblage over place is relatively fragile (Dawney, 2013). Experiences such as this - micro-breaks in the atmosphere of the city centre at night - can be found in various moments and practices in the night-time city.

\section{Conclusion: Atmospheres of the Night-Time City Centre}

This paper has aimed to explore in greater the detail the possible connection between the concepts of atmosphere and the assemblage. It has proposed that atmospheres can be viewed as 'placed assemblage', whereby the practices which make up the assemblage have worked to tie it to a place. What we experience as atmosphere - as the buzz, sensation and feeling of the city centre at night cannot be described as 'an economy'. The night-time city is not the night-time economy: it is a 
vibrating, pulsating atmosphere. It differs from day as a variety of affects and practices gain traction within a particular space-time and generate this atmosphere. The empirical material discussed reveals a constant on-going work in the creation and maintenance of the night-time city centre atmosphere. Bars, clubs and restaurants thus form just one group of materials and practices which make atmosphere out of assemblage, bringing together people, objects, ideas, affects and discourses. In this paper, I have focused on three of these practices: boundary making; diversity of actors; and, the coexistence of these actors within a particular time and place. In doing so, this paper has developed the relationship between assemblage and atmosphere as concepts (Anderson, 2009). This understanding of atmosphere as a 'placed assemblage' helps in grasping their simultaneous strength and power; their materiality and immateriality. Crucially, I feel that this offers a much better description of the night-time city than the phrase 'night-time economy' ever has. However, neither phrase ('night-time economy' and 'night-time atmosphere) should be understood as singular: both refer to a level of plurality. In particular, the sensing of an atmosphere is conditioned by the body, and differing atmospheres may be sensed by differing individuals.

The inter-disciplinary field of 'night-time economy studies' emerged in the mid-1990s, with Hollands' 1995 paper Friday Night, Saturday Night standing as an obvious marker of the birth of this area of study (Hollands, 1995). The last few years have seen this area of research reach maturity, with overviews from a number of disciplinary positions presenting a clear indication that this is now a well-developed field (Jayne et al., 2011a; Nicholls, 2009; Roberts and Eldridge, 2009). Furthermore, engagement with debates about urban illumination (Edensor, 2012) and requests for consideration of a broader range of actors in the night (Eldridge and Roberts, 2013) indicate a desire for a continued evolution in our understanding of urban nights. Still, social scientists have so far only begun to touch upon the ways in which experience of the urban night is differentiated by gender (Waitt et al., 2011), religion (Valentine et al., 2010), race (Talbot, 2004) and other segmentations. We have also failed to integrate studies of sexuality with the urban night, despite some of the obvious connections (Hubbard, 2005). Furthermore, our geographical sensibility of the night is narrow. This paper does not move beyond the night-time city centre, but we need more studies of suburbs, towns, homes, workplaces and community centres at night: in other words, places and spaces which are not the city centre streets or the bars which surround them.

Through the recognition of the importance of interpreting assemblage as (an) 'arranging', this paper seeks to build upon a growing body of literature that has emphasised the contingent, constructed nature of urban spaces. Assemblage offers us a new ontology and epistemology of the city. This demands, then, that we rethink our objects of research and how we conceptualise them. 'Night-time economy' is thus just one concept that requires a reconceptualization. More broadly, we might begin to think what an assemblage approach towards the city can help us understand about the city more generally. If assemblages incorporate a range of actors and practices, what role might night play as an active participant in generating the city? In this paper, I have offered an affective atmosphere as a description of the city centre at night. However, there are probably multiple types of night in different social-cultural contexts. How do these different nights interact? What is their connection to the 'natural night'? At the moment, 'night-time economy studies' has led us down a path towards this nightography; it is now up to us to step through the door. 


\section{$\underline{\text { References }}$}

Adams, M., Moore, G., Cox, T., Croxford, B., Refaee, M., Sharples, S., 2007. The 24-Hour City: Residents' Sensorial Experiences. The Senses and Society 2 (2), 201-215.

Adey, P., 2012. How to engage? Assemblage as ethos/ethos as assemblage. Dialogues in Human Geography 2 (2), 198-201.

Adey, P., Bissell, D., 2010. Mobilities, Meetings, and Futures: An Interview with John Urry. Environment and Planning D: Society and Space 28 (1), 1-16.

Adey, P., Brayer, L., Masson, D., Murphy, P., Simpson, P., Tixier, N., 2013. 'Pour votre tranquillité': Ambiance, atmosphere, and surveillance. Geoforum (Online Early Access).

Anderson, B., 2009. Affective Atmospheres. Emotion, Space and Society 2 (2), 77-81.

Anderson, B., Harrison, P., 2010. The Promise of Non-Representational Theories, in: Anderson, B., Harrison, P. (Eds.), Taking Place: Non-Representational Theories and Human Geography. Ashgate, London.

Anderson, B., Kearnes, M., McFarlane, C., Swanton, D., 2012. On assemblages and geography. Dialogues in Human Geography 2 (2), 171-189.

Anderson, B., McFarlane, C., 2011. Assemblage and Geography. Area 43 (2), 124-127.

Bell, D., 2008. Destination drinking: Toward a research agenda on alcotourism. Drugs: Education, Prevention, and Policy 15 (3), 291-304.

Bennett, J., 2005. The Agency of Assemblages and the North American Blackout. Public Culture 17 (3), 445-466.

Bianchini, F., 1995. Night Cultures, Night Economies. Planning Practice \& Research 10 (2), 121-126.

Bissell, D., 2010. Passenger mobilities: affective atmospheres and the sociality of public transport. Environment and Planning D: Society and Space 28 (2), 270-289.

Boyle, A., Wee, N., Harris, R., Tompkins, A., Soper, M., Porter, C., 2009. Alcohol-related emergency department attendances, preloading and where are they drinking? Cross-sectional survey. Emergency Medicine Journal 26 (Supplement 1), 27.

Brennan, T., 2004. The Transmission of Affect. Cornell University Press, Ithaca, NY.

Chatterton, P., Hollands, R., 2001. Changing our "Toon": youth, nightlife and urban change in Newcastle. University of Newcastle upon Tyne, Newcastle upon Tyne, England.

Chatterton, P., Hollands, R., 2002. Theorising Urban Playscapes: Producing, Regulating and Consuming Youthful Nightlife City Spaces. Urban Studies 39 (1), 95-116.

Comedia, 1991. Out of Hours: A study of economic, social and cultural life in twelve town centres in the U.K. Comedia, London. 
Cooper, J., Murray, R., Nelson, J., 2010. Taxi! Urban Economies and the Social and Transport Impacts of the Taxicab. Ashgate Publishing, Farnham.

de Certeau, M., 1984. The Practice of Everyday Life. University of California Press, Berkeley.

Dawney, L. 2013. The interruption: investigating subjectivation and affect. Environment and Planning D: Society and Space 31 (4), 628-644

Deleuze, G., Guattari, F., 1987. A Thousand Plateaus : Capitalism and Schizophrenia. University of Minnesota Press, Minneapolis.

Doel, M.A., 1996. A hundred thousand lines of flight: a machinic introduction to the nomad thought and scrumpled geography of Gilles Deleuze and Felix Guattari. Environment and Planning D: Society and Space 14 (4), 421-439.

Edensor, T. 2012. 'Illuminated atmospheres: anticipating and reproducing the flow of affective experience in Blackpool', Environment and Planning D: Society and Space, 30(6), 1103-1122.

Eldridge, A., 2010. Public panics: problematic bodies in social space. Emotion, Space and Society 3 (1), 40-44.

Eldridge, A., Robert, M. 2013. Re-populating the Nighttime City: Hospitality and Gender, in: Henckel, D., Thomaier, S., Könecke, B., Zedda, R., Stabilini, S. (Eds), Space-Time Design of the Public City. Springer, London, pp49-60

Gallan, B., Gibson, C., 2011. New dawn or new dusk? Beyond the binary of day and night. Environment and Planning A 43 (11), 2509-2515.

Gibson-Graham, J.K., 2008. Diverse economies: performative practices for 'other worlds'. Progress in Human Geography 32 (5), 613-632.

Graham, S., Thrift, N., 2007. Out of Order: Understanding Repair and Maintenance. Theory, Culture and Society 24 (3), 1-25.

Griffin, C., Bengry-Howell, A., Hackley, C., Mistral, W., Szmigin, I., 2009. 'Every Time I Do It I Absolutely Annihilate Myself': Loss of (Self-)Consciousness and Loss of Memory in Young People's Drinking Narratives. Sociology 43 (3), 457-476.

Guattari, F., 1995. Chaosmosis: An Ethico-Aesthetic Paradigm. Powet, Sydney.

Guattari, F., 2006. The Anti-Oedipus Papers. Semiotext(e), New York.

Hadfield, P., 2006. Bar Wars: Contesting the Night in Contemporary British Cities. Oxford University Press, Oxford.

Hadfield, P., Lister, S., Hobbs, D., Winlow, S., 2001. The '24-hour City' - condition critical. Town and Country Planning 70 (11), 300-302.

Hadfield, P., Lister, S., Traynor, P., 2009. 'This town's a different town today': Policing and regulating the night-time economy. Journal of Criminology and Criminal Justice 9 (4), 465-485. 
Harman, G., 2009. Prince of Networks: Bruno Latour and Metaphysics. re.press, Prahran, VIC, Australia.

Harrison, P., 2011. flētum: a prayer for X. Area 43 (2), 158-161.

Heath, T., 1997. The Twenty-Four Hour City Concept-A Review of Initiatives in British Cities. Journal of Urban Design 2 (2), 193-204.

Helms, G., Atkinson, R., MacLeod, G., 2007. Securing the City: Urban Renaissance, Policing and Social Regulation. European Urban and Regional Studies 14 (4), 267-276.

Herod, A., Aguiar, L.L.M., 2006. Introduction: Cleaners and the Dirty Work of Neoliberalism. Antipode 38 (3), 425-434.

Hobbs, D., Hadfield, P., Lister, S., Winlow, S., 2003. Bouncers: violence and governance in the nighttime economy. Oxford University Press, Oxford.

Hobbs, D., Winlow, S., Hadfield, P., Lister, S., 2005. Violent Hypocrisy: Governance and the Nighttime Economy. European Journal of Criminology 2 (2), 161-183.

Hollands, R., 1995. Friday Night, Saturday Night. Department of Social Policy, Newcastle University, Newcastle-upon-Tyne.

Hubbard, P., 2005. The Geographies of going out: emotion and embodiment in the evening economy, in: Davidson, J., Bondi, L., Smith, M. (Eds.), Emotional geographies. Ashgate, Aldershot, pp. 117-135.

Jackson, P., 2004. Inside Clubbing. Berg, Oxford.

Jayne, M., Holloway, S.L., Valentine, G., 2006. Drunk and Disorderly: Alcohol, Urban Life and Public Space. Progress in Human Geography 30 (4), 451-468.

Jayne, M., Valentine, G., Holloway, S.L., 2008. The place of drink: Geographical contributions to alcohol studies. Drugs: education, prevention, policy 15 (3), 219-232.

Jayne, M., Valentine, G., Holloway, S.L., 2010. Emotional, embodied and affective geographies of alcohol, drinking and drunkenness. Transactions of the Institute of British Geographers 35 (4), 540554.

Jayne, M., Valentine, G., Holloway, S.L., 2011a. Alcohol, Drinking, Drunkenness: (Dis)Orderly Spaces. Ashgate, Aldershot.

Jayne, M., Valentine, G., Holloway, S.L., 2011b. What use are units? Critical geographies of alcohol policy. Antipode 44 (3), 828-846.

Jayne, M., Gibson, C., Waitt, G., Valentine, G. 2012. Drunken mobilities: Backpackers, alcohol, 'doing place'. Tourist Studies 12 (3), 211-231

Latour, B., 1987. Science in Action. Harvard University Press, Cambridge, MT. 
Latour, B., 2002. Gabriel Tarde and the end of the social, in: Joyce, P. (Ed.), The Social in Question. Routledge, London, pp. 117-132.

Latour, B., 2005. Reassembling the Social. Oxford University Press, Oxford.

Latour, B., 2007. A Plea for Earthly Sciences. bruno-latour.fr.

Latour, B., 2009. The Making of Law: An Ethnography of the Conseil d'État. Polity Press, Cambridge.

Malbon, B., 1999. Clubbing: dancing, ecstasy and vitality. Routledge, London.

McCann, E., Ward, K., 2011. Urban Assemblages, in: McCann, E., Ward, K. (Eds.), Mobile Urbanism. University of Minnesota Press, Minneapolis, pp. xiii-xxxv.

McCormack, D., 2008. Engineering affective atmospheres: On the moving geographies of the 1897 Andree expedition. Cultural Geographies 15 (4), 413-430.

McFarlane, C., 2009. Translocal assemblages: space, power and social movements. Geoforum 40 (4), 561-567.

McFarlane, C., 2011. Assemblage and critical urbanism. City 15 (2), 204-224.

McFarlane, C., Anderson, B., 2011. Thinking with assemblage. Area 43 (2), 162-164.

Measham, F., Brain, K., 2005. 'Binge' drinking, British alcohol policy and the new culture of intoxication. Crime, Media, Culture 3 (1), 262-283.

Measham, F., Moore, K., 2009. Repertoires of distinction: Exploring patterns of weekend polydrug use within local leisure scenes across the English night time economy. Criminology and Criminal Justice 9 (4), 437-464.

Montgomery, J., 1990. Cities and the art of cultural planning. Planning Practice \& Research 5 (3), 17 24.

Mulgan, G., Worpole, K., 1986. Saturday Night or Sunday Morning. Comedia, London.

Nandrea, L., 1999. "Graffiti Taught Me Everything I Know about Space": Urban Fronts and Borders. Antipode 31 (1), 110-116.

Nayak, A., 2006. Displaced Masculinities: Chavs, Youth and Class in the Post-industrial City. Sociology 40 (5), 813-831.

Nicholls, J., 2009. The Politics of Alcohol. Manchester University Press, Manchester.

Pain, R., Townshend, T., 2002. A safer city centre for all? Senses of 'community safety' in Newcastle upon Tyne. Geoforum 33 (1), 105-119.

Phillips, J., 2006. Agencement/Assemblage. Theory, Culture \& Society 23 (2-3), 108-109.

Roberts, M., 2006. From 'creative city' to 'no-go areas' - The expansion of the night-time economy in British town and city centres. Cities 23 (5), 331-338. 
Roberts, M., Eldridge, A., 2009. Planning the Night-time City. Routledge, London.

Roberts, M., Turner, C., 2005. Conflicts of Liveability in the 24-Hour City: Learning from 48 Hours in the Life of London's Soho. Journal of Urban Design 10 (2), 171 - 193.

Shaw, R., 2010. Neoliberal Subjectivities and the Development of the Night-Time Economy in British Cities. Geography Compass 4 (7), 893-903.

Talbot, D., 2004. Regulation and racial differentiation in the construction of night-time economies: a London case study. Urban Studies 41 (4), 887-901.

Talbot, D., 2007. Regulating the Night: Race Culture and Exclusion in the Making of the Night-time Economy. Ashgate, Aldershot.

Thurnell-Read, T., 2011. Off the Leash and Out of Control: Masculinities and Embodiment in Eastern European Stag Tourism. Sociology-the Journal of the British Sociological Association 45 (6), 977-991.

Valentine, G., Holloway, S.L., Jayne, M., 2010. Contemporary cultures of abstinence and the nighttime economy: Muslim attitudes towards alcohol and the implications for social cohesion. Environment and Planning A 42 (1), 8-22.

Vall, N., 2007. Cities in Decline? A Comparative History of Malmö and Newcastle After 1945. Högskola, Malmö.

van Liempt, I., van Aalst, I., 2012. Urban Surveillance and the Struggle between Safe and Exciting Nightlife Districts. Surveillance and Society 9 (3).

Waitt, G., Jessop, L., Gorman-Murray, A., 2011. 'The guys in there just expect to be laid': embodied and gendered socio-spatial practices of a 'night out' in Wollongong, Australia. Gender, Place \& Culture 18 (2), 255-275. 